\title{
The Prevalence of Self-Medication With Painkillers Among Iraqi Medical Students
}

\author{
Ahmed Al-Imam ${ }^{1,2}$, Marek A. Motyka ${ }^{3}$, Mahmoud Mishaal $^{1}$, Shireen Mohammad ${ }^{4}$, \\ Nooralhuda Sameer ${ }^{4} \&$ Hala Dheyaa ${ }^{4}$ \\ ${ }^{1}$ Department of Anatomy and Cellular Biology, College of Medicine, University of Baghdad, Iraq \\ ${ }^{2}$ CERVO Brain Research Centre, Faculty of Medicine, University of Laval, Canada \\ ${ }^{3}$ Institute of Sociological Sciences, University of Rzeszow, Rzeszow, Poland \\ ${ }^{4}$ College of Medicine, University of Baghdad, Iraq \\ Correspondence: Ahmed Al-Imam, Department of Anatomy and Cellular Biology, College of Medicine, \\ University of Baghdad, Iraq. E-mail: ahmed.al-imam.1@ulaval.ca
}

Received: March 30, 2020 Accepted: April 23, 2020 Online Published: May 8, 2020

doi:10.5539/gjhs.v12n7p38 URL: https://doi.org/10.5539/gjhs.v12n7p38

\begin{abstract}
Background: The use of painkillers is widespread worldwide, some people experience unwanted side effects, and some may overuse them. Self-medication is the selection and use of medicines by individuals to treat self-recognized illnesses and collateral symptoms.
\end{abstract}

Objectives: We aim to determine the prevalence and pattern of self-medication with painkillers among a population of undergraduate medical students in Baghdad.

Methods: We carried out a cross-sectional study, via convenient sampling, among 502 medical students ( $\mathrm{n}=502)$ from the University of Baghdad, Al-Mustansirya University, Al-Kindy University, Al-Nahrain University, and Al-Iraqia University. We distributed an anonymous online questionnaire to the students. The survey included questions on demographic variables and information on self-medicating with painkillers during the academic year of 2018-2019.

Results: The prevalence of use of painkillers was $68.73 \%, 73 \%$ were females, and $27 \%$ were males. There was a statistically significant association between gender and the use of analgesics. Still, there was no statistically significant association between the academic level of students and analgesic use. The frequency of analgesic use per month was less than once (34.5\%) of the participants, 1-3 times (37.1\%), 4-6 times (14.2\%), 7-9 times (7\%), $10-12$ times $(3.1 \%)$, and more than 13 times (4\%) of the participants. Most of the respondents $(68 \%)$ reported that there was no difference in use between regular college days and exam days. The most common cause of use was headache $(71 \%)$ for males and females, while dysmenorrhea was the second most common cause among female participants $(36 \%)$. The most common source of information about analgesics relied on by the respondents was from friends $(50.1 \%)$, family members, pharmacists, textbooks, the internet, and nurses. The most commonly used drug was Acetaminophen.

Conclusion: Self-medication with analgesics is highly prevalent among undergraduate medical students in Baghdad, and we need to raise the awareness of the public on the potentials of addictive behavior.

Keywords: addiction medicine, analgesics, Iraq, medical students, medical undergraduates, pain, self-medication, substance abuse, substance-related disorders

\section{Introduction}

An analgesic or painkiller is any member of the group of drugs used to achieve analgesia and relief from pain (World Health Organization, 2009). Self-medication is a critical topic in connection with self-care and defined as the selection and use of medicines by individuals to treat self-recognized ailments and symptoms (World Health Organization, 2009). Non-prescription or over-the-counter (OTC) drugs are common in developing countries, including Iraq, where self-medication is a common practice as it provides a low-cost alternative for people who cannot afford the expensive and overwhelmed clinical service. In contrast, several drugs such as Acetaminophen and non-steroidal anti-inflammatory drugs (NSAIDs) are available as OTC drugs (Hussain, Malik, Hameed, 
Ahmad, \& Riaz, 2010). Besides, the World Health Organization pointed out that responsible self-medication could be helpful in the prevention and treatment of diseases that do not require medical consultation while providing a cost-effective alternative medicine for common illnesses (World Health Organization, 1995). NSAIDs, most of which are available as OTC, are sufficient for managing pain and are safe at a low dose of administration. NSAIDs are useful for short-term use only because the long-term usage or taking high doses can lead to a plethora of adverse effects, including gastrointestinal bleeding, cardiovascular complications, and renal problems (Sostres, Gargallo, Arroyo, \& Lanas, 2010). Another commonly used OTC analgesic is Acetaminophen, also known as Paracetamol, for which plentiful of studies on self-medication found that it is the most widely used drug to relieve pain and fever (Wynne \& Long, 1996). Nevertheless, a dangerous effect of Acetaminophen is hepatotoxicity, and it may culminate in acute liver failure, especially when taken in high doses by individuals who are alcoholics (Schiødt, Rochling, Casey, \& Lee, 1997).

Self-medication captivates special attention among the medical students because they represent the future healthcare professionals and because they are in extensive direct contact with patients during their medical practice (James, Handu, Al Khaja, Otoom, \& Sequeira, 2006; Zafar et al., 2008). Prior research attempts among medical and non-medical students worldwide have reported that the utilization of OTC drugs among university students is familiar with a prevalence that varies among different countries depending on the cultural traits, socioeconomic backgrounds, and the overall settings of the study. The majority of these studies were from countries other than Iraq. Sarahroodi et al. (2012) surveyed university students in central Iran and confirmed that $76.6 \%$ self-medicated with painkillers (Sarahroodi, Maleki-Jamshid, Sawalha, Mikaili, \& Safaeian, 2012). A similar study at King Abdul-Aziz University in Saudi Arabia reported that $75.2 \%$ of the participants used painkillers without seeking any medical advice over six months, while in rural medical colleges in Brazil, the prevalence was $49.7 \%$ (Albusalih, Naqvi, Ahmad, \& Ahmad, 2017; Batista, de Oliveira, \& de Souza Corrêa, 2017). The primary objective of our study is to assess the prevalence of self-medication with analgesics among undergraduate medical students in Baghdad.

\section{Participants and Methods}

\subsection{Study Design}

We implemented a cross-sectional study design that we deployed in July 2019 among undergraduate medical students from all academic levels at the University of Baghdad, Al-Mustansirya University, Al-Kindy University, Al-Nahrain University, and Al-Iraqia University for the academic year 2018-2019. We distributed an anonymous online questionnaire, via Google Forms online platform, to the students following the distribution of written informed consent.

\subsection{Sampling Procedure}

We utilized the following formula to calculate the precise sample size to obtain accurate results that are internally valid and representative for the targeted population. Accordingly, we calculated a projected sample size of 383 participants. Later, we carried out a pilot study on 20 randomly selected students, following which we adjusted the study design. Eventually, we achieved an actual total sample size of 502 students that were representative for both sexes and all academic levels (stages) within each university, while using a convenient sampling method.

$$
\frac{\mathrm{Z} 2 * \mathrm{p}(1-\mathrm{p}) / \mathrm{e}^{2}}{1+\left(\mathrm{Z}^{2} * \mathrm{p}(1-\mathrm{p}) / \mathrm{e}^{2} \mathrm{~N}\right)}
$$

\subsection{The Questionnaire}

The questionnaire consisted of three sections. The first section included questions in connection with the demographics of participants and whether or not the participant had self-medicated with analgesics in the past academic year. The second section explored the respondents who answered with "no" regarding self-medication, to inquire about the etiology of why they opted not to self-medicate. The third section was for the participants who answered with "yes", and it included questions about the frequency of analgesic use, the most common cause behind taking an analgesic, which drug they used the most, why they did not seek professional medical advice, the source of information about the drugs of choice, whether or not there was a difference in their patterns of use of painkillers between regular college days and exam days, the most commonly used drug, and whether they read the drug information leaflet or not.

\subsection{Statistical Analysis}

We analyzed the data using the Statistical Package for the Social Sciences (SPSS v.21). We applied the Chi-square test to assess the relation of gender and academic level with the use of analgesics, at a cutoff p-value of 0.05 for 
evaluating the theoretical statistical significance.

\subsection{Ethical Approval}

The institutional review board at the department of community medicine [College of Medicine, University of Baghdad] approved the study protocol. The authors carried out the work described in this manuscript following the Code of Ethics of the World Medical Association (Declaration of Helsinki) on medical research involving human subjects, EU Directive (210/63/EU) on the protection of animals used for scientific purposes, Uniform Requirements for manuscripts submitted to biomedical journals and the ethical principles defined in the Farmington Consensus of 1997.

\section{Results}

A total of 502 participants completed the questionnaire, out of which $343(68.32 \%)$ were females, and 159 $(32.67 \%)$ were males. The age of the participants ranged between 17-28 years, with the majority between 19-22 years old. The participants were from all the academic levels (stages) with the following frequencies: 92 participants (18.33\%) from the first stage, $82(16.33 \%)$ from the second stage, $141(28.09 \%)$ from the third stage, $59(11.75 \%)$ from the fourth stage, $44(8.77 \%)$ from the fifth stage, and $84(16.73 \%)$ from the sixth stage. Out of the 502 respondents, $345(68.73 \%)$ answered "yes" to the question about self-medicating with painkillers, and 157 (31.27\%) responded with "no". Out of the 345 participants who self-medicated with painkillers, 254 (73.62\%) were females, and $91(26.38 \%)$ were males. The 157 participants who did not self-medicate with painkillers declared their rationale for their chosen behavior, and $40.76 \%$ replied that they did not need any painkillers. Almost one quarter $(26.75 \%$ ) who did not self-medicate claimed that they did not want to make a habit out of using painkillers, and $22.29 \%$ said that they do not use any medications without prior medical advice from a physician. $8.92 \%$ feared possible side effects or contraindications associated with the use, and $1.27 \%$ have previous experience of unwanted adverse effects while using painkillers.

Concerning the reasons that led the students to self-medicate with analgesics, the most common were headache ( $71 \%, 51 \%$ in females versus $49 \%$ in males) (Figure 1). Dysmenorrhea was the second most common cause among female participants $(36 \%)$. Flu $(26 \%)$, toothache $(12 \%)$, gastrointestinal pain $(10 \%)$, muscle ache $(10 \%)$, joint pain $(9 \%)$, for general well-being $(4.9 \%)$, urinary tract pain $(2.3 \%)$ represented the other causes behind self-medication. When asked about the reasons why they did not seek medical advice, $76.2 \%$ thought their illness was mild, $19.4 \%$ reported lack of time, $2.3 \%$ thought that visiting a doctor is costly, $1.7 \%$ have no trust in doctors, and less than $1 \%$ said that the nearest clinic was distant. As for the information sheet of the drug, 57.4\% reported that they read it, as opposed to $42.6 \%$ who did not. The respondents declared that the most common source of information on self-medication drugs was from friends and family members $(50.1 \%)$, pharmacists $(22.9 \%)$, textbooks $(20.8 \%)$, the internet $(5.8 \%)$, and nurses $(<1 \%)$. The drugs that participants used the most to self-medicate were: Acetaminophen (Paracetamol) (63.7\%), Mefenamic acid (Ponstan) (12.7\%), Ibuprofen (Profen) (10.1\%), and Diclofenac (Voltaren) (4.6\%). In comparison, $10 \%$ used other drugs like Norgesic, Co-Algesic, Aspirin tablets, and soluble formulae.

We applied the Chi-square test and detected a statistically significant association between gender and the use of analgesics (p-value $<0.001$ ) (Table 1). The prevalence of self-medication with painkillers among different academic stages were: the first stage $(57.6 \%)$, the second stage $(69.5 \%)$, the third stage $(68.8 \%)$, the fourth stage $(69.5 \%)$, the fifth stage (79.5\%), and the sixth stage (73\%). Based on Chi-square testing, there was no statistically significant association between the academic level of students and the self-medicating behavior ( $\mathrm{p}$-value $=0.120$ ) (Table 2). The frequency of monthly use of analgesics was: less than once (34.5\%), 1-3 times (37.1\%), 4-6 times (14.2\%), 7-9 times (7\%), 10-12 times (3.1\%), and more than 13 times (4\%). $20 \%$ of the participants reported that they used painkillers more during exams, and $11.6 \%$ during regular college days, while $68.4 \%$ experienced no variations in the patterns of use between regular days and exams. 


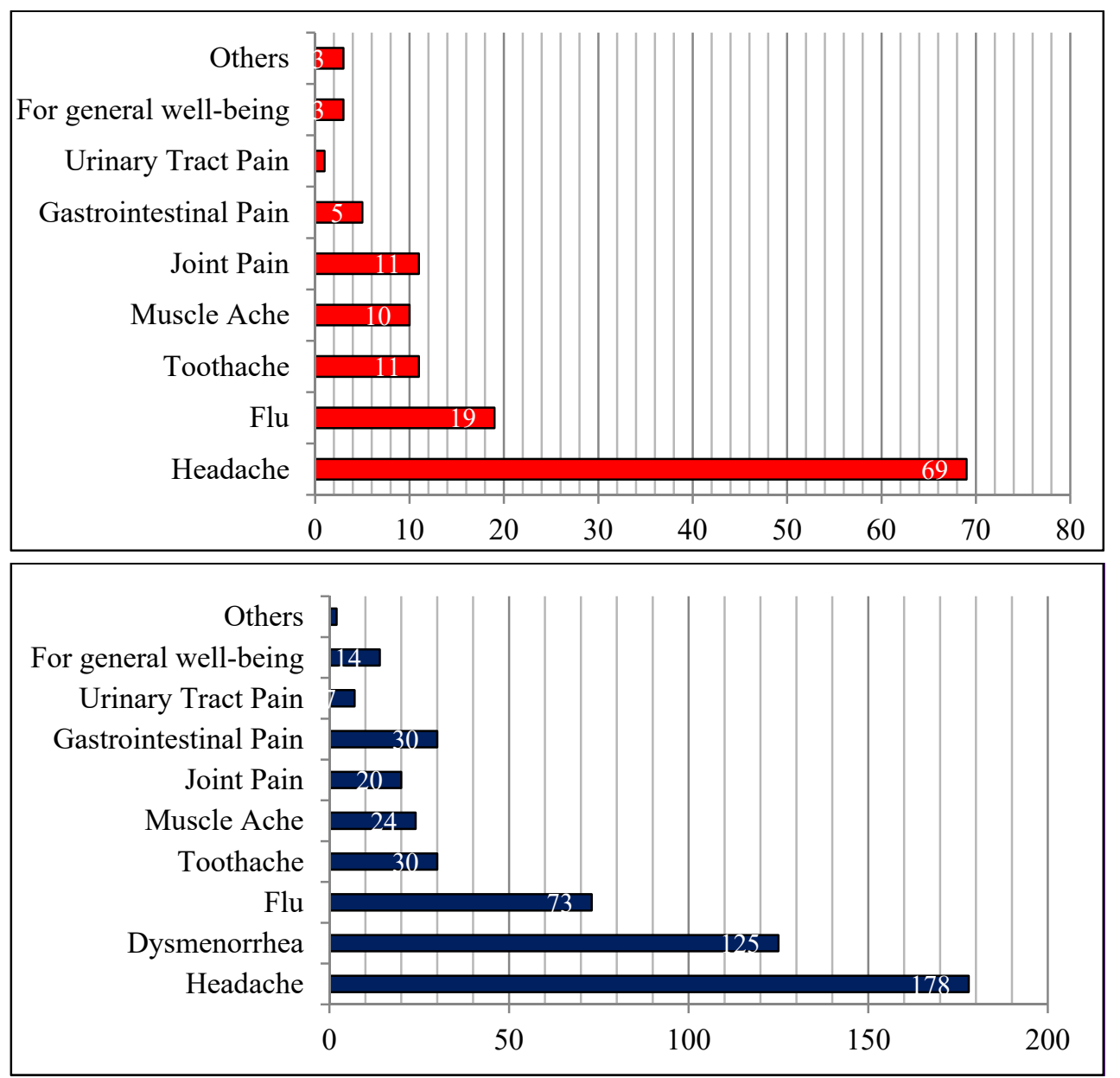

Figure 1. Causes of Self-medication with Painkillers: Male [upper] and Female Participants [lower].

Table 1. The Association of Gender and Self-Medication with Analgesics

\begin{tabular}{|c|c|c|c|c|c|c|}
\hline & & \multicolumn{2}{|l|}{ Use } & & \multirow{2}{*}{ Total } & \\
\hline & & Yes & No & & & \\
\hline \multirow{2}{*}{ Gender } & Female & 254 & 89 & \multicolumn{3}{|c|}{343} \\
\hline & Male & 91 & 68 & \multicolumn{3}{|c|}{159} \\
\hline \multicolumn{2}{|l|}{ Total } & 345 & 157 & \multicolumn{3}{|c|}{502} \\
\hline \multicolumn{7}{|c|}{ Chi-Square Tests } \\
\hline & & Value & df & $\begin{array}{l}\text { Asymp. Sig. } \\
\text { (2-sided) }\end{array}$ & $\begin{array}{l}\text { Exact Sig. } \\
\text { (2-sided) }\end{array}$ & $\begin{array}{l}\text { Exact Sig. } \\
\text { (1-sided) }\end{array}$ \\
\hline \multicolumn{2}{|c|}{ Pearson Chi-Square } & $14.299^{\mathrm{a}}$ & 1 & $<0.001$ & & \\
\hline \multicolumn{2}{|c|}{ Continuity Correction ${ }^{\mathrm{b}}$} & 13.528 & 1 & $<0.001$ & & \\
\hline \multicolumn{2}{|c|}{ Likelihood Ratio } & 13.946 & 1 & $<0.001$ & & \\
\hline \multicolumn{2}{|c|}{ Fisher's Exact Test } & & & $<0.001$ & $<0.001$ & $<0.001$ \\
\hline \multicolumn{2}{|c|}{ Linear-by-Linear Association } & 14.271 & 1 & $<0.001$ & & \\
\hline \multicolumn{2}{|c|}{$\mathrm{N}$ of Valid Cases } & 502 & & & & \\
\hline
\end{tabular}

a. 0 cells $(.0 \%)$ have expected count less than 5 . The minimum expected count is 49.73 .

b. Computed only for a $2 \times 2$ table. 
Table 2. The Association of the Academic Level (Stage) and Self-Medication with Analgesics

\begin{tabular}{|c|c|c|c|c|c|}
\hline & & \multicolumn{3}{|l|}{ Use } & \multirow{2}{*}{ Total } \\
\hline & & Yes & No & & \\
\hline \multirow{6}{*}{ Stage } & First & 53 & 39 & \multicolumn{2}{|r|}{92} \\
\hline & Second & 57 & 25 & \multicolumn{2}{|r|}{82} \\
\hline & Third & 97 & 44 & \multicolumn{2}{|r|}{141} \\
\hline & Fourth & 41 & 18 & \multicolumn{2}{|r|}{59} \\
\hline & Fifth & 35 & 9 & \multicolumn{2}{|r|}{44} \\
\hline & Sixth & 62 & 22 & \multicolumn{2}{|r|}{84} \\
\hline \multicolumn{2}{|c|}{ Total } & 345 & 157 & \multicolumn{2}{|r|}{502} \\
\hline \multicolumn{6}{|c|}{ Chi-Square Tests } \\
\hline & & & Value & df & $\begin{array}{c}\text { Asymp. Sig. } \\
\text { (2-sided) }\end{array}$ \\
\hline \multicolumn{3}{|c|}{ Pearson Chi-Square } & $8.737^{\mathrm{a}}$ & 5 & .120 \\
\hline \multicolumn{3}{|c|}{ Likelihood Ratio } & 8.695 & 5 & .122 \\
\hline \multicolumn{3}{|c|}{ Linear-by-Linear Association } & 5.993 & 1 & .014 \\
\hline \multicolumn{3}{|c|}{$\mathrm{N}$ of Valid Cases } & 502 & & \\
\hline
\end{tabular}

a. 0 cells $(.0 \%)$ have expected count less than 5 . The minimum expected count is 13.76 .

\section{Discussion}

\subsection{The Prevalence of Analgesic Use}

In our study, the prevalence of self-medication with painkillers was almost two-thirds of the total sample size (68.73\%). Similar studies from Saudi Arabia, Brazil, and Iran showed a prevalence of $76.6 \%, 49.8 \%$, and 82\%, respectively (Albusalih et al., 2017; Batista et al., 2017; Sarahroodi et al., 2012). A survey in Serbia showed that the prevalence of self-medication among medical students was $79.9 \%$, while the use of analgesics accounted for 55.4\% (Lukovic et al., 2014).

In the Iraqi population, Al-Ameri et al. (2017) confirmed a high prevalence of self-medication (92.4\%), of which $40.1 \%$ self-medicated with analgesics (Al Ameri, Badri, Husham, \& Lafta, 2017). The same study also stated that self-medication among health-related colleges was significantly lower than other disciplines of science, which is in concordance with a study from Nigeria by Esan and coworkers (2018) (Al Ameri et al., 2017; Esan et al., 2018). On the contrary, a study from Egypt revealed that medical students self-medicated significantly more than non-medical students do (Helal \& Abou-ElWafa, 2017). In Jordan, Alshogran and associates (2018), compared between medical and non-medical students and showed that the prevalence of self-medication was $96 \%$ for both groups, but the use of analgesics was higher in medical student ( $82 \%$ as opposed to $73 \%$ in non-medical students, p-value $=0.013$ ) (Alshogran, Alzoubi, Khabour, \& Farah, 2018).

Several studies among Polish medical students indicated high levels of self-treatment (Sowa et al., 2015; Wójtowicz-Chomicz \& Borzęcki, 2011; Zwinczewska, Zwinczewska, Domka, \& Ryniak, 2016). According to a survey among students of six Polish medical universities, almost $98 \%$ of respondents confirmed the use of OTC drugs in the last 12 months, and over $60 \%$ reported that they self-treated for simple health problems (Zwinczewska et al., 2016). According to the respondents, factors conducive to the frequent use of OTC drugs included: easy availability, encouraging advertisements, and satisfactory therapeutic effects, while $99 \%$ were aware that OTC drugs could cause dangerous side effects, and $88 \%$ never consulted their doctor (Zwinczewska et al., 2016). Sowa and coworkers (2015) confirmed that $90 \%$ of their research sample admitted self-treatment, especially with OTC drugs, although only $6 \%$ believe that such drugs are fully safe (Sowa et al., 2015). The study participants justified their self-treatment by the ease of access to OTC drugs $(56 \%)$, previously tested expected effects $(36 \%)$, and attractive price (16\%) (Sowa et al., 2015). The most commonly used drugs were "cold and flu" medicines, analgesics, and anti-inflammatory drugs (Sowa et al., 2015). 
In the Norwegian population, the prevalence was 47\% (Dale et al., 2015). Earlier research attempts in 2003 from the United Kingdom, showed that medical students and healthcare professionals are facing difficulties when seeking healthcare for themselves, partially because of the competitive environment that they work in, where high commitment and discipline are mandatory (Chew-Graham, Rogers, \& Yassin, 2003). The heterogeneity in results among different studies can be attributable to the spatial and temporal dimensions where the researchers conducted their investigations, differences in between societies and their associated ethnic and religious backgrounds, and demographic parameters, and the socioeconomic status, as well as the sample size in those studies.

\subsection{Association with Gender}

Among our study participants who self-medicated with painkillers, $73 \%$ were females, and $27 \%$ were males. Besides, the Chi-square test confirmed a statistically significant difference based on gender, which is agreeable with other studies from Iran, Brazil, Serbia, Poland, Nigeria, Norway, the United Kingdom, and Germany (Barrenberg, Knopf, \& Garbe, 2018; Batista et al., 2017; Chew-Graham et al., 2003; Dale et al., 2015; Esan et al., 2018; Lukovic et al., 2014; Sarahroodi et al., 2012; Zwinczewska et al., 2016). However, other studies showed no statistically significant association between gender and analgesic use (Al Ameri et al., 2017; Albusalih et al., 2017).

\subsection{Association with Academic Level}

Our participants were from all six stages at their medical colleges, and the majority who self-medicated were from the fifth stage, which is consistent with those from Saudi Arabia, where the majority of users were from higher academic years (Albusalih et al., 2017). However, there was no statistically significant association as opposed to other studies from Brazil, Serbia, and Slovenia (Batista et al., 2017; Klemenc-Ketis, Hladnik, \& Kersnik, 2010; Lukovic et al., 2014). We may explain this phenomenon by assuming that that medical students gain more medical knowledge about drugs and their pharmacodynamics as they progress towards senior years in their studies. As a result, they may feel safer when self-medicating compared to their younger colleagues. Also, senior students are under much stress due to the long hours of medical training during their clinical placement, which renders them under more physical as well as psychological stresses (Klemenc-Ketis et al., 2014).

\subsection{Causes of Analgesic Use}

In our study, the most common reason for taking painkillers in both sexes was headache (71\%), which is in harmony with the international research output from Iran, Iraq, Nigeria, as well as Jordan (Al Ameri et al., 2017; Alshogran et al., 2018; Esan et al., 2018; Sarahroodi et al., 2012). Headache is a non-specific symptom that associate with many physiological pathologies, including those of the nervous system, which interferes with the routine daily functioning and lifestyle (Mayo Clinic, 2019). Hence, it is the most prevalent cause of self-medication with analgesics. It is also closely related to stress, for example, tension headache, and it has been found that medical students use painkillers for headaches significantly more than non-medical students (Alshogran et al., 2018; Dagistani, Al Hejaili, Binsalih, Al Jahdali, \& Al Sayyari, 2016). On the other hand, a study from Brazil reported that dysmenorrhea was more frequent than headaches among female participants who self-medicated with analgesics (Batista et al., 2017; Mannix, 2008). Zwinczewska found similar results in Poland, where $72 \%$ of women reached for analgesics due to menstrual pains and $61 \%$ due to non-migraine headaches (Zwinczewska et al., 2016).

\subsection{Relation to Exams, and Reasons to Self-Medicate}

Albeit the stressful and long hours of study during exams, $68 \%$ of students reported no difference in their self-medicating behavior for exams versus routine college days, which is consistent with the Serbian study by Lukovic and colleagues, which validated the absence of any significant association with the time spent by participants in studying ( $\mathrm{p}=0.095$ ) (Lukovic et al., 2014). When we asked about why they opted to self-medicate instead of consulting a doctor, the majority (76\%) answered that they thought their illness represents a mild condition, which goes in line with other studies from Serbia, Iraq, and Egypt (Al Ameri et al, 2017; Helal \& Abou-ElWafa, 2017; Lukovic et al., 2014). Surprisingly, in Nigeria, students attributed their self-medication tendencies to the unfriendly attitude of healthcare workers at their school clinic (Esan et al., 2018). On the other hand, Polish students explained that the main reason for the use of painkillers was the lack of time to visit a doctor (75\%) (Wójtowicz-Chomicz \& Borzęcki, 2011).

\subsection{Source of Information on Drugs, and Drug Leaflets}

Concerning our study participants, the most common source of information on medications was friends and family members, which goes in line with the results from an Iranian study (Sarahroodi et al., 2012). In Egypt, medical students most commonly relied on information from pharmacists, while in Serbia, most participants relied on their 
knowledge and personal experience (Helal \& Abou-ElWafa, 2017; Lukovic et al., 2014). Further, in Egypt, the majority of the study participants (57\%) read the drug information leaflet (Helal \& Abou-ElWafa, 2017). Additionally, Jordanian medical students read the drug brochures significantly more than non-medical students $(\mathrm{p}=0.016)$ (Alshogran et al., 2018).

\subsection{Drugs of Choice}

The most commonly used drug among our participants was Acetaminophen (Paracetamol), which is consistent with results from other studies from Iran, Saudi Arabia, Brazil, Nigeria, and the United Kingdom (Albusalih et al., 2017; Batista et al., 2017; Chew-Graham et al., 2003; Esan et al., 2018; Sarahroodi et al., 2012). Acetaminophen is readily available in pharmacies and other healthcare facilities as an over-the-counter medication, and there is a widespread belief that Acetaminophen is the least toxic of analgesics (Aminoshariae \& Khan, 2015; Schiødt et al., 1997). In contrast to our study, researchers from Germany confirmed that a non-steroidal anti-inflammatory drug, Ibuprofen, was the most used drug by their study participants (Barrenberg et al., 2018). In Poland, It was surprising that over $20 \%$ of students confirmed the use of a combination of OTC drugs with alcohol (Zwinczewska et al., 2016).

\subsection{Future Studies on Self-Medication}

Researchers should enhance the reliability of anticipated studies and augment the implied level-of-evidence, for instance, by conducting systematic reviews, also known as meta-reviews, that can encompass metanalytics, as well prospective studies (Al-Imam \& AbdulMajeed, 2017a; Al-Imam, 2017a; the Centre for Evidence-Based Medicine, 2011; the Centre for Evidence-Based Medicine, 2016). Future studies should also aim to evaluate the use of narcotics versus non-narcotic analgesics among subgroups of the population of interest in undergraduate medical students, including athletes and individuals with addictions, as they may have different explanatory and predictive factors towards self-medication (Al-Imam A, Al-Mukhtar, Shafiq, Irfan, \& Saleh, 2017; Al-Imam, 2017a; Catalani et al., 2018). It is also necessary to survey existing groups on the web, including the infamous deep web, where web users can anonymously explore, discuss, and purchase controlled as well as illicit substances, including opioids and psychoactive substances via online illicit e-markets on the Darknet marketplace (Al-Imam \& Al-Imam, 2017; Al-Imam et al., 2016; Al-Imam, 2017a; Al-Imam, 2017b; Catalani et al., 2018). Ambitious behavioral scientists can deploy real-time analyses and predictive models of machine learning to infer the spatio-temporal variabilities to prevent potential self-medication "epidemics" (Al-Imam \& Abdul Majeed, 2017b; Al-Imam \& Al-Lami, 2020; Al-Imam \& Motyka, 2019; Al-Imam, 2018; Al-Imam, 2019a; Al-Imam, 2019b; Al-Imam, 2020a; Al-Imam, 2020b; Al-Imam, Sahai, Al-Derzi, Al-Shalchy, \& Abdullah, 2019). Consequently, the cumulative knowledge will allow policymakers to carry out risk assessments, economic evaluations, guidelines, and international protocols to limit this phenomenon.

\section{Conclusion}

The prevalence of painkillers use among undergraduate medical students in Baghdad is high (68.73\%). Females self-medicated with painkillers significantly more than males. At the same time, there was no significant association between self-medication patterns and the academic level of the students as well as no increment in the usage of drugs during examination periods. We strongly opine that there should be more awareness regarding the safe and appropriate use of painkillers to avoid potential adverse effects, toxicities, and fatalities among the youth. The main limitation of this study is that it implemented a cross-sectional design rather than a prospective study that can be vital to follow up on the probable temporal and spatial variabilities. Besides, recall bias cannot be excluded, in addition to the social interaction and the exchange of information between the students while filling the questionnaire that might jeopardize the internal validity of the research.

\section{Contribution of Authors}

Ahmed Al-Imam co-supervised the study, developed the discussion section of the article, revised the manuscript for scholarly submission, and corresponded with the journal's editorial office. Marek A. Motyka revised the manuscript and developed its discussion section. Mahmoud Mishaal coordinated the research group. Shireen Mohammad, Nooralhuda Sameer, and Hala Dheyaa distributed the survey, collected the responses, and conducted data curation and statistical analyses with SPSS, and wrote the first draft of the manuscript.

\section{Acknowledgments}

The authors would like to express gratitude to the students who responded to our survey.

\section{Source of Funding}

The authors self-funded this study. 


\section{Competing Interests Statement}

The authors declare that they have no conflict of interest.

\section{References}

Al Ameri, R. J., Badri, A., Husham, J., \& Lafta, R. K. (2017). Prevalence of self-medication among university students in Baghdad: a cross-sectional study from Iraq. EMHJ-Eastern Mediterranean Health Journal, 23(2), 87-93. https://doi.org/10.26719/2017.23.2.87

Albusalih, F. A., Naqvi, A. A., Ahmad, R., \& Ahmad, N. (2017). Prevalence of self-medication among students of pharmacy and medicine colleges of a public sector university in Dammam City, Saudi Arabia. Pharmacy, 5(3), 51. https://doi.org/10.3390/pharmacy5030051

Al-Imam, A. (2017a). Retrospective Analyses of High-risk NPS: Integrative Analyses of PubMed, Drug Fora, and the Surface Web. Global Journal of Health Science, 9(11), 40-50. https://doi.org/10.5539/gjhs.v9n11p40

Al-Imam, A. (2017b). Monitoring and Analysis of Novel Psychoactive Substances in Trends Databases, Surface Web and the Deep Web, with Special Interest and Geo-Mapping of the Middle East (Master s thesis, University of Hertfordshire, Hertfordshire, United Kingdom). Retrieved from https://uhra.herts.ac.uk/handle/2299/19462

Al-Imam, A. (2018). 25b-NBOMe: a case report of sudden death and insightful view of Google trends data. Iranian Journal of Psychiatry and Behavioral Sciences, 12(1), 1-5. https://doi.org/10.5812/ijpbs.9870

Al-Imam, A. (2019a). Inferential Analysis of Big Data in Real-Time: One Giant Leap for Spatiotemporal Digital Epidemiology in Dentistry. Odontostomatology Research Anatomy Learning \& Implantology, 12(1), 1-14.

Al-Imam, A. (2019b). Optimizing Linear Models via Sinusoidal Transformation for Boosted Machine Learning in Medicine. Journal of the Faculty of Medicine Baghdad, 61(3,4), 1-9.

Al-Imam, A. (2020a). Novel Psychoactive Substances Research: On the Necessity of Real-time Analytics and Predictive Modelling. Research and Advances in Psychiatry, 7(1) [in press].

Al-Imam, A. (2020b). A Novel Method for Computationally Efficacious Linear and Polynomial Regression Analytics of Big Data in Medicine. Modern Applied Science, 14(5), 1-10.

Al-Imam, A., \& AbdulMajeed, B. A. (2017a). Novel Psychoactive Substances: Systematic Review and Evidence-Based Analysis of Literature. Global Journal of Health Science, 9(11), 1-13. https://doi.org/10.5539/gjhs.v9n11p1

Al-Imam, A., \& AbdulMajeed, B. A. (2017b). The NPS Phenomenon and the Deep Web: Internet Snapshots of the Darknet and Potentials of Data Mining. Global Journal of Health Science, 9(11), 86-101. https://doi.org/10.5539/gjhs.v9n11p86

Al-Imam, A., \& Al-Lami, F. (2020). Machine Learning for Potent Dermatology Research and Practice. Journal of Dermatology and Dermatologic Surgery, 24(1), 1-4. https://doi.org/10.4103/jdds.jdds_54_19

Al-Imam, A., \& Motyka, M. (2019). On the necessity for paradigm shift in psychoactive substances research: the implementation of machine learning and artificial intelligence. Alcoholism and Drug Addiction/Alkoholizm $i$ Narkomania, 32(3), 237-242. https://doi.org/10.5114/ain.2019.91004

Al-Imam, A., Al-Mukhtar, F., Shafiq, A., Irfan, M., \& Saleh, M.M. (2017). Knowledge and (Ab)Use in Connection with Novel Psychoactive Substances: A Cross-Sectional Analysis of Iraqi Medical Students. Global Journal of Health Science, 9(11), 61-70. https://doi.org/10.5539/gjhs.v9n11p61

Al-Imam, A., Sahai, A., Al-Derzi, A. R., Al-Shalchy, A., \& Abdullah, F. (2019). "All Models Are Wrong, But Some Are Useful": On the Non-Bayesian Statistical Robustness of Hilton's Law. The European Journal of Anatomy, 24(1), 75-78.

AL-Imam, A., Santacroce, R., Roman-Urrestarazu, A., Chilcott, R., Bersani, G., Martinotti, G., \& Corazza, O. (2016). Captagon: use and trade in the Middle East. Human Psychopharmacology: Clinical and Experimental, 32(3), 1-8. https://doi.org/10.1002/hup.2548

Al-Imam, M. L., Al-Imam, A. (2017). Knowledge and (Ab) Use in Connection with Novel Psychoactive Substances: A Cross-Sectional Analysis of Psychedelic Users Existing on Online Platforms. Global Journal of Health Science, 9(11), 51-60. https://doi.org/10.5539/gjhs.v9n11p51 
Alshogran, O. Y., Alzoubi, K. H., Khabour, O. F., \& Farah, S. (2018). Patterns of self-medication among medical and nonmedical University students in Jordan. Risk Management and Healthcare Policy, 11, 169-176. https://doi.org/10.2147/RMHP.S170181

Aminoshariae, A., \& Khan, A. (2015). Acetaminophen: old drug, new issues. Journal of Endodontics, 41(5), 588-593. https://doi.org/10.1016/j.joen.2015.01.024

Barrenberg, E., Knopf, H., \& Garbe, E. (2018). Over-The-Counter (OTC) Drug Consumption among Adults Living in Germany: Results from the German Health Interview and Examination Survey for Adults 2008-2011 (DEGS1). Pharmacy, 6(2), 52. https://doi.org/10.3390/pharmacy6020052

Batista, P., de Oliveira, A. D. S., \& de Souza Corrêa, C. (2017). Automedicação entre acadêmicos de Enfermagem. [Self-medication among nursing students]. Revista Eletrônica Acervo Saúde / Electronic Journal Collection Health, 9, S841-S848. https://doi.org/10.25248/REAS71_2017

Catalani, V., Prilutskaya, M., Al-Imam, A., Marrinan, S., Elgharably, Y., Zloh, M., ... Corazza, O. (2018). Octodrine: New Questions and Challenges in Sport Supplements. Brain Sciences, 8(2), 34. https://doi.org/10.3390/brainsci8020034

Chew-Graham, C. A., Rogers, A., \& Yassin, N. (2003). 'I wouldn't want it on my CV or their records': medical students' experiences of help-seeking for mental health problems. Medical Education, 37(10), 873-880. https://doi.org/10.1046/j.1365-2923.2003.01627.x

Dagistani, A., Al Hejaili, F., Binsalih, S., Al Jahdali, H., \& Al Sayyari, A. (2016). Stress in Medical Students in a Problem-Based Learning Curriculum. International Journal of Higher Education, 5(3), 12-19. https://doi.org/10.5430/ijhe.v5n3p12

Dale, O., Borchgrevink, P. C., Fredheim, O. M. S., Mahic, M., Romundstad, P., \& Skurtveit, S. (2015). Prevalence of use of non-prescription analgesics in the Norwegian HUNT3 population: Impact of gender, age, exercise and prescription of opioids. BMC Public Health, 15(1), 461. https://doi.org/10.1186/s12889-015-1774-6

Esan, D. T., Fasoro, A. A., Odesanya, O. E., Esan, T. O., Ojo, E. F., \& Faeji, C. O. (2018). Assessment of Self-Medication Practices and Its Associated Factors among Undergraduates of a Private University in Nigeria. Journal of Environmental and Public Health, 2018. https://doi.org/10.1155/2018/5439079

Helal, R. M., \& Abou-ElWafa, H. S. (2017). Self-medication in university students from the city of Mansoura, Egypt. Journal of Environmental and Public Health, 2017. https://doi.org/10.1155/2017/9145193

Hussain, S., Malik, F., Hameed, A., Ahmad, S., \& Riaz, H. (2010). Exploring health seeking behavior, medicine use and self medication in urban and rural Pakistan. Southern Med Review, 3(2), 32-35.

James, H., Handu, S. S., Al Khaja, K. A., Otoom, S., \& Sequeira, R. P. (2006). Evaluation of the knowledge, attitude and practice of self-medication among first-year medical students. Medical Principles and Practice, 15(4), 270-275. https://doi.org/10.1159/000092989

Klemenc-Ketis, Z., Hladnik, Z., \& Kersnik, J. (2010). Self-medication among healthcare and non-healthcare students at University of Ljubljana, Slovenia. Medical Principles and Practice, 19(5), 395-401. https://doi.org/10.1159/000316380

Lukovic, J. A., Miletic, V., Pekmezovic, T., Trajkovic, G., Ratkovic, N., Aleksic, D., \& Grgurevic, A. (2014). Self-medication practices and risk factors for self-medication among medical students in Belgrade, Serbia. PloS one, 9(12), e114644. https://doi.org/10.1371/journal.pone.0114644

Mannix, L. K. (2008). Menstrual-related pain conditions: dysmenorrhea and migraine. Journal of Women's Health, 17(5), 879-891. https://doi.org/10.1089/jwh.2007.0440

Mayo Clinic. Tension headache. Retrieved 26 March, 2020, from https://www.mayoclinic.org/diseases-conditions/tension-headache/symptoms-causes/syc-20353977

Sarahroodi, S., Maleki-Jamshid, A., Sawalha, A. F., Mikaili, P., \& Safaeian, L. (2012). Pattern of self-medication with analgesics among Iranian University students in central Iran. Journal of Family \& Community Medicine, 19(2), 125-129. https://doi.org/10.4103/2230-8229.98302

Schiødt, F. V., Rochling, F. A., Casey, D. L., \& Lee, W. M. (1997). Acetaminophen toxicity in an urban county hospital. New England Journal of Medicine, 337(16), 1112-1118. https://doi.org/10.1056/NEJM199710163371602 
Sostres, C., Gargallo, C. J., Arroyo, M. T., \& Lanas, A. (2010). Adverse effects of non-steroidal anti-inflammatory drugs (NSAIDs, aspirin and coxibs) on upper gastrointestinal tract. Best Practice \& Research Clinical Gastroenterology, 24(2), 121-132. https://doi.org/10.1016/j.bpg.2009.11.005

Sowa, M., Kołłątaj, W., Kołłątaj, B., Karwat, I., \& Szakuła, J. (2015). Samoleczenie wśród studentów medycyny Uniwersytetu Medycznego w Lublinie. [Self-medication practice among medical students of Medical University in Lublin]. Journal of Education, Health and Sport, 5(7), 439-452.

The Centre for Evidence-Based Medicine. Explanation of the 2011 OCEBM Levels of Evidence. Retrieved 27 March, 2020, from https://www.cebm.net/archives/1120

The Centre for Evidence-Based Medicine. OCEBM Levels of Evidence. Retrieved 27 March, 2020, from https://www.cebm.net/archives/63

Wójtowicz-Chomicz, K., \& Borzęcki, A. (2011). Stosowanie leków przeciwbólowych z grupy OTC przez studentów Wydziału Lekarskiego UM w Lublinie. [Administration of OTC analgesics among students of Medical University in Lublin]. Family Medicine \& Primary Care Review, 13(2), 254-256.

World Health Organization. (1995). Report of the WHO expert committee on national drug policies. Contribution to updating the WHO guidelines for developing national drug policies. Geneva: WHO.

World Health Organization. (2009). Self-care in the context of primary health care (No. SEA-HSD-320). WHO Regional Office for South-East Asia.

Wynne, H. A., \& Long, A. (1996). Patient awareness of the adverse effects of non-steroidal anti-inflammatory drugs (NSAIDs). British Journal of Clinical Pharmacology, 42(2), 253-256. https://doi.org/10.1046/j.1365-2125.1996.41420.x

Zafar, S. N., Syed, R., Waqar, S., Zubairi, A. J., Vaqar, T., Shaikh, M., ... \& Saleem, S. (2008). Self-medication amongst university students of Karachi: prevalence, knowledge and attitudes. Journal of the Pakistan Medical Association, 58(4), 214-217.

Zwinczewska, H., Zwinczewska, D., Domka, J., \& Ryniak, P. (2016). Postawy i zwyczaje studentów medycyny w Polsce związane z samoleczeniem lekami OTC. [Attitudes and habits of Polish Medical Students towards self-medication with OTC drugs]. Zeszyty Naukowe Towarzystwa Doktorantów Uniwersytetu Jagiellońskiego. Nauki Ściste, 13, 7-20.

\section{Copyrights}

Copyright for this article is retained by the author(s), with first publication rights granted to the journal.

This is an open-access article distributed under the terms and conditions of the Creative Commons Attribution license (http://creativecommons.org/licenses/by/4.0/). 